\title{
CITY LOGISTICS: SAMPLE IMPLEMENTATION OF IZMIR CITY
}

\author{
DOI: 10.17261/Pressacademia.2018.964 \\ JMML- V.5-ISS.3-2018(5)-p.206-213
}

\section{Yucel Ozturkoglu ${ }^{1}$, Melisa Ozbiltekin ${ }^{2}$, Nazlican Gozacan ${ }^{3}$, Irmak Surgec ${ }^{4}$}

${ }^{1}$ Yaşar University, Izmir, Turkey.

yucel.ozturkoğlu@yasar.edu.tr, ORCID: 0000-0002-9569-8178

${ }^{2}$ Yaşar University, Izmir, Turkey.

melisaozbiltekin@hotmail.com, ORCID: 0000-0002-1356-3203

${ }^{3}$ Yaşar University, Izmir, Turkey.

nazlicangozacan@outlook.com, ORCID: 0000-0003-3876-4826

${ }^{4}$ Yaşar University, Izmir, Turkey.

irmaksurgec@gmail.com, ORCID: 0000-0002-7605-0800

Date Received: June 19, 2018

Date Accepted: September 24, 2018

To cite this document

Ozturkoglu, Y., Ozbiltekin, M., Gozacan, N., Surgec, I. (2018). City logistics: sample implementation of Izmir city. Journal of Management, Marketing and Logistics (JMML), V.5(3), p.206-213.

Permemant link to this document: $\underline{\text { http://doi.org/10.17261/Pressacademia.2018.964 }}$

Copyright: Published by PressAcademia and limited licenced re-use rights only.

\begin{abstract}
Purpose- In spite of the rapidly growing population, especially in big cities due to different reasons (migration, employment and education opportunities etc.), the life areas and resources of the cities are depleted rapidly due to unplanned construction and unconscious use of resources. In order to leave more livable cities and habitats to future generations, the concept of sustainable cities is very important. In this study, city logistics was examined in terms of the concept of sustainability and the effect of sustainability on city logistics was focused. In the first study, a detailed literature on sustainable city was investigated.

Methodology- The questionnaire form, which consists of 150 participants who have been living in İmir for at least ten years, has been answered. Statistical methods were used to evaluate the concept of sustainable city according to gender, age and educational status.

Findings- According to the results of the survey, the province of İzmir was examined in terms of a sustainable city; weaknesses and strengths were highlighted and solutions were proposed for the future. In addition, it was found that there was a significant difference in sustainable city perception according to education, age and gender.

Conclusion- According to the results obtained within the scope of the study, solutions were proposed for the future. As a solution suggestion, the subway stations have been examined and it has been proposed to add Peron Separator Door Systems and to arrange the sensible floors according to the said system.
\end{abstract}

Keywords: Sustainability, SWOT analysis, city logistic, transportation, city planning.

JEL Classification: M30, N70, R40

\section{ŞEHIR LOJISTIĞi: IZMIR ILI ÖRNEK UYGULAMASI}

\section{ÖZET}

Amaç- Özellikle büyük şehirlerde farklı sebeplerden (göç, istihdam ve eğitim olanakları vb.) dolayı hızla artan nüfusa rağmen şehirlerin sahip olduğu yaşam alanları ve kaynaklar, plansız yapılaşma ve kaynakların bilinçsiz kullanma sonucu her geçen gün hızla tükenmektedir. Gelecek nesillere, daha yaşanabilir şehirler ve yaşam alanları bırakabilmek için sürdürülebilir şehirler kavramı oldukça önem arz etmektedir. $\mathrm{Bu}$ çalışma da şehir lojistiği, sürdürülebilirlik kavramının açısından incelenmiş ve sürdürülebilirliğin şehir lojistiğine yarattığı etkiye odaklanılmıştır. Çalışma da ilk olarak sürdürülebilir şehir konusundan detaylı bir literatür araştırılması yapılmıştır.

Metodoloji- Çalışmanın örneklemini oluşturan ve İzmir ilinde en az on yıldır yaşayan 150 katılımcı düzenlenen anket formunu cevaplanmıştır. Sürdürülebilir şehir kavramının cinsiyet, yaş ve eğitim durumlarına göre değerlendirilmesi için istatistiki yöntemler kullanılmıştır.

Bulgular- Anket sonuçlarına göre İzmir ili sürdürülebilir bir şehir açısından irdelenmiş; zayıf ve güçlü yönleri ön plana çıkartılarak geleceğe yönelik çözüm önerilerinde bulunulmuştur. Ayrıca, eğitim, yaş ve cinsiyete göre sürdürülebilir şehir algısında anlamlı bir farklılık olduğu tespit ediliştir. 
Sonuç- Çalışma kapsamında elde edilen sonuçlara göre geleceğe yönelik çözüm önerilerinde bulunulmuştur. Çözüm önerisi olarak metro istasyonları incelenmiş Peron Ayırıcı Kapı Sistemleri'nin eklenmesi ve hissedilebilir zeminlerin söz konusu sisteme göre düzenlenmesi güvenlik amacıyla önerilmiştir.

Anahtar Kelimeler: Sürdürülebilirlik, SWOT analizi, şehir lojistiği, ulaşım, şehir planlama.

JEL Kodları: M30, N70, R40

\section{GiRiş}

Uzun yıllardan beri süregelen nüfus artışı, küreselleşme, teknolojik gelişmeler; enerji kullanımını arttırdığı gibi, kırsal alanlardan şehirlere doğru yapılan yer değiştirmelerin de artmasıyla trafik yoğunluğu, hava ve gürültü kirliliğinin artışı, emniyet yetersizlikleri gibi problemler ortaya çıkmıştır. 2011 yılı itibari ile Türkiye'de nüfusun yüzde 77, 2'si kentsel alanlarda yaşamaktadır (Keskin, 2016). 2023 yılı için bu oran yüzde 82 olarak tahmin edilmektedir (Keskin, 2016). Mutlak nüfus artışının yanında kentli nüfus artışı da iç tüketimde belirleyici olmaktadır. Kentleşme ve kentsel dönüşüm ile yaşam tarzlarındaki değişimin etkileri, lojistik ihtiyacının öngörülmesinde kullanılmaktadır (Tanyaş, 2013). Şehir lojistiği, şehir içerisindeki lojistik faaliyetlerin incelenmesi, planlanması, sürdürülmesi ve iyileştirilmesi konularını kapsayan lojistik alanıdır. Bu terim büyük şehirlerde ortaya çıkan lojistik operasyonlarının planlanmasında oluşan sorunları en aza indirmek adına oluşturulmuştur. Şehir lojistiği için dikkat edilmesi gereken en önemli nokta geçici olmayan çözümler değil, geleceği de koruyabilecek çözümler elde edilmesidir. Bu sürecin oluşturulmasında; enerji israfı, gürültü gibi çevresel etkiler, kalifiye işgücü ihtiyacı, çalışma sermayesine duyulan ihtiyaç ya da trafik sııışılığı gibi sorunlar yaşanabilmektedir. Bu sürecin ana hedefleri düşük maliyet, yüksek kalite ile sosyal yaşamdaki ve ulaşımdaki verimliliği arttırma ve bu verimliliğin sürdürülebilir olmasıdır.

Şehirdeki planlamalar ve lojistik açıdan kümelenmeler yeterli bir şekilde yapılmadığından, nüfusun yoğun olduğu yerlerde; şehir alanlarııın genişlemesine ve sanayi alanlarının, garajların, toptancıların, taşımacılık şirketlerinin, depoların, gümrük gibi iş bölgelerinin şehir içinde kalmasına sebep olmaktadır. Şehir lojistiğindeki eksikliklerin bir başka sonucu olarak; alımsatım işlemleri internet üzerinden gerçekleşse dahi malların fiziki teslimatı "online" şekilde gerçekleşmemesidir (Kurt, 2010). Günümüzdeki kentler oluşturdukları etkin ve verimli ulaşım sistemleriyle yatırım ve ticaret alanında dünya çapında bir rekabet içindelerdir. Bu nedenle verimli ve çevre dostu lojistik sistemler kentlere, ekonomik gelişmişlik alanında rekabet edebilmeleri için yardımcı olmaktadır (Taniguchi ve Tamagawa, 2005).

Şehir lojistiğindeki her politika ve alınacak her önlem tüm kamu ve özel sektör kuruluşlarının istekleri dikkate alınarak yapılmalıdır. Kamu sektörü hükümet, belediyeler; trafik, altyapı, demiryolu terminali, liman ve havalimanı otoriteleri gibi "yönetici-idareci" kısmını içeren taraf grubudur. Şehir içerisinde yaşayan vatandaşlar da idarecilerle ortak noktalarda buluşabildiğinden aynı grup içerisinde gösterilebilirler. Özel sektördeki taraflar ise tedarikçiler, üreticiler, taşıma komisyoncuları, taşımacılık firmaları, depo firmaları, lojistik firmaları, mağazalardan oluşmaktadır. Bu taraf grubu için 'lojistik hizmet verenler', 'yük gönderenler/tedarikçiler' ve 'yük alanlar/müşteriler' de denilebilir(Çalışkan vd. 2017). Kamu tarafı ve özel sektör tarafı genel olarak ortak çıkarlara sahip değildir. İdareciler ekonomik açıdan düşünüp, yaşanabilir bir şehir yaratma amacına sahipken; özel sektör tarafları düşük maliyet ile zamanında ve kaliteli hizmet amacı gütmektedir. İki taraf için de ortak bir amaç bulunması "şehir lojistiğinde başarılı olunabilir" anlamına gelir. Ancak, genelde şehir lojistiği çalışmaları yöneticilerin amaçları doğrultusunda yapılmaktadır.

Bu çalışmada İzmir 'deki ulaşımın sürdürebilirlik ve erişilebilirlik açısından analiz edilmesi amaçlanmıştır. Yapılan çalışma iki ana bölümden oluşmaktadır. Birinci bölümde daha önce şehir lojistiği ile ilgili yapılmış olan çalışmalar anlatılmıştır. İkinci bölümde ise İzmir ulaşımının sürdürülebilirliğini ve erişebilirliğini tehlikeye atan noktaları kişilerin sorulara verdikleri yanıtlarla tespit edip ulaşım ağının bu yönde gelişimini sağlamak için alternatif çözüm yollarının üretilmesi amaçlanmıştır. Bu amaç doğrultusunda İzmir Büyükşehir Belediyesi Konak ilçesi iç̧in hazırlanan "izmir Tarih Sürdürülebilir Ulaşım Projesi" kapsamında kullanılan anket, yapılacak çalışmaya göre uyarlanmış ve en az 10 yıldır İzmir 'de ikamet eden 150 kişiye uygulanarak ortaya çıkan sonuçlar analiz edilmiştir.

\section{LITERATÜR TARAMASI}

Literatürde şehir lojistiğiyle ilgili çok sayıda çalışma olmasına rağmen, şehirlerin kendine has özellikleri dikkate alınarak yapılan çalışma sayısı oldukça azdır. Çalışmalar genellikle toplu taşımadaki sorunlar ve bunların giderilmesi için sunulan öneriler üzerinedir. Bunun yanında; şehir içindeki ve şehre yakın lojistik köyler, şehir içi yük taşımacılığı ve şehir içi trafiği de sıkça işlenen konulardandır. Yapılan çalışmalardan bazıları belediyeler tarafından onaylanmış ve uygulanmalarına izin verilmiştir. Erel vd. (1995) çalışmalarında Türk Ulaştırma Sistemi'ndeki veri toplama faaliyetleri ile ilgili sorunlara değindikten sonra istenilen veri tabanını oluşturmak üzere bir model önermektedirler. Haldenbilen vd. (1999) Denizli'deki kent içi yolcu taşıma sistemlerini incelemişlerdir. Ulaşım sistemleri incelenerek ekonomi yönünden irdelenmiş ve mevcut sorunların çözümü için öneriler sunulmuştur. Yazar (2006) ülkemizde sürdürülebilir kentsel gelişmenin sağlanabilmesi için 
kentlerin kentsel politika içerisindeki yerlerini almalarından ve mevcut sistemlerin kalkındırılarak daha iyi kentsel planlamaların oluşturulmasından bahsetmiştir. Özalp ve Öcalır (2008) Türkiye'deki kentsel ulaşım planlamasındaki sistematik yapıyı formüle etmek ve düzensizliği aşmak amacıyla Türk kentlerindeki kentsel ulaşım çalışma ve planları, incelemiş ve kapsamlı bir şekilde kronolojik sıralama içerisinde değerlendirmişlerdir. Anand vd. 2012 yılında yaptıkları çalışmada şehir içi lojistiğinin modellenebilmesi için 5 farklı perspektif oluşturmuşlardır. Bunun yanında Spence vd. (2009), kentleşmenin büyümedeki rolü ile ilgili daha iyi bir anlayış yaratmak ve kentleşmenin ortaya koyduğu zorluklarla mücadele etmek amacıyla bir model geliştirmişlerdir. Ayrıca kentleşmenin, günlük yaşam alanları üzerindeki etkilerini detaylıca incelemişlerdir. Bu alanlar içerisinde günlük ulaşım hatları ve lojistik de yer almaktadır. Comendador vd. (2012) GPS teknolojisini kullanarak ulaştıkları gerçek veriler ile İspanya'da bulunan iki farklı şehrin yük taşımacılığını incelemişlerdir. Yalınız vd.(2011) Eskişehir'in kent merkezindeki park sorunundan yola çıkarak sürdürülebilir bir yaklaşım içerisinde "park et ve bin" sisteminin uygunluğu ve uygulanabilirliğini analiz etmişlerdir. Yalınız vd. (2011) öncelikli olarak Kütahya kentindeki toplu taşıma sistemini ve mevcut ulaşım sorunlarını ele almışlardır. Daha sonra bu sorunlar çeşitli yönlerden değerlendirilmiş ve toplu taşıma kullanımını artırmak amacıyla birkaç öneride bulunmuşlardır. Dodson vd. (2011) şehir içinde kullanılan toplu taşıma hatlarının planlanması üzerinde durmuşlardır. Ağ planlamasını çeşitli açılardan ele almış ve üç kitleye hitap edecek şekilde özetlemişlerdir. Saatçioğlu ve Yaşarlar (2012) i̇stanbul'un ulaşım sorunlarını ortaya koymuşlar ve bu sorunlara çözüm bulmaya çalışmışlardır. Toplu taşıma sistemlerini sınıflandırarak hem ekonomik hem de sosyal açıdan karşılaştırmışlardır. Bunun sonucunda İstanbul'daki yeni ulaştırma sistemlerini de içeren kent içi toplu taşımaya çözüm önerileri getirmişlerdir. Gülhan vd. (2013),Denizli'deki toplu taşıma planlama sürecinde yer alan etkinlik göstergelerini tespit etmişlerdir. Bunun üzerine çeşitli senaryolar oluşturularak bunlardan hangisinin daha etkili olduğu belirlenmiştir. Önemli çalışmalardan biri olan CIVITAS girişimi ile şehir lojistiğindeki gelişmelerin ele alındığı makale Van Rooijen ve Quak(2014) CIVITAS' ın, Avrupa şehirlerinde uygulanan yenilikçi kentsel yük taşımacılığı uygulamaları ele alınmıştır. Bu uygulamaların farklı tedbir ve sonuçları sunulmuştur. Cirit (2014) kentlerin temel ulaşım verileri üzerinde durmuştur. Farklı yolculuk taleplerine ve güzergâh uzunluklarına göre toplu taşıma sistemlerinin seçimine ilişkin analiz yapmıştır. Yapılan analizler ve elde edilen bulgular sonucunda kentsel lojistiğin daha iyi olabilmesi adına öneriler sunmuştur. Tadic vd. (2015) kentsel lojistiğin uygulamalarının ne kadar zor olduğunu göstermek amacıyla lojistik zincirlerinin uygulanmasına ilişkin mevcut durum ve ilişkileri irdelemişlerdir. Alternatif çözümlerin tanımlanması, etkilerin modellenmesi ve değerlendirilmesi yoluyla kentsel lojistiğin tüm aşamaları için bütünleşmiş bir yaklaşım sunmuşlardır. Başka bir yaklaşım ile İnaç ve Tanyaş 2012 yılında İstanbul'un şehir içi lojistik problemlerini ele alarak Analitik Hiyerarşi Prosesi (AHP) ile öncelikli sıralama oluşturmuşlardır. Akbulut (2016), kentsel ulaşım faaliyetlerini ele alarak kent içi ulaşım stratejilerini bütüncül bir yaklaşımla gözden geçirmiş ve sürdürülebilirlik çerçevesinde, kent içi ulaşımda karşılaşılan sorunlara çözüm önerileri sunmuştur. Kentsel toplu taşıma türleri ele alıp ulaşım sistemlerinin karşılaştırmasını yaparak sorunlara çözüm önerileri sunmuştur. Lindholm (2010) çalışmasında şehir içi yük taşımacılığının çevresel etkilerini ele almıştır. Erdumlu (2006) İstanbul'da lojistik bölge kurulumu için şehir lojistiği ve lojistik köy kavramlarını ele almış, şehir lojistiği kavramı çerçevesinde modeller geliştirmiş ve bu modelleri karşılaştırarak büyüklük ve yer tayini yapmıştır. 2010 yılında Morana ve Gonzales-Feliu tarafından yapılan çalışmada şehir içi lojistiğinin sürdürülebilirlik boyutu dikkate alınmış, sürdürülebilirliğin 3 temel ayağı olan ekonomik çevresel ve sosyal boyut ele alınmıştır. Çalışkan vd. (2017) Türkiye'de kentsel lojistiğe ait, araştırılması gereken alanları ortaya çıkarmışlardır. Bu amaç doğrultusunda; göz ardı edilen konular belirlenmiş, yapılan çalışmalar arasında kıyaslama yapılmıştır. Böylece çalışıması gereken alanlar belirlenmiş ve Şehir lojistiği ile ilgili ihmal edilen noktalara dikkat çekmek istenmiştir. Sabegh vd. (2016) İzmir ilini yeşil sanayi açısından değerlendirmişlerdir. Dalgakıran ve Öztürkoğlu (2017) Türkiye'de kentsel lojistik gelişmişliği ile mobilya sektörü arasındaki ilişkiyi değerlendirmişlerdir. 2014 yılında Crainic ve Ricciardi tarafından yapılan çalışmada, şehir içi yük dağıtımının verimli şekilde organize olması amaçlanmıştır. Diğer araştırma konuları gibi şehir lojistiği için de kamu sektörüne ve özel sektöre bağlı olarak paydaşlarının incelenmesi önem verilen bir konudur. Bu yaklaşım ile 2005 yılında Taniguchi ve Tamagawa şehir lojistiğinin taraflarını (kamu sektörü ve özel sektör açısından) ele alan bir çalışma yapmışlardır. Benzer şekilde 2009 yılında, Zhang ve Wu şehir içi lojistiğinin paydaşlarını içeren bir yöntem oluşturmuşlardır. 2012 yılında Büyüközkan vd. benzer şekilde şehir içi lojistiğinin paydaşlarını ele alan bir çalışma yapmıştır. Karadeniz ve Akpınar (2011) Trabzon ili için Türkiye'deki lojistik köy uygulamalarını ve çalışmalarını incelemişlerdir. Edinilen bilgiler ışığında Trabzon ilinin kentsel lojistik alanındaki konumu ve lojistik açısından aktifliği ortaya çıkmıştır. 2015 yılında Taniguchi vd. şehir lojistiğinin problemlerini tanımlamak ve modeller geliştirmek için bir dizi bilgi ve veri gerektiğini savunmuşlardır. Verimliliğin artırılması ve şehir içindeki mal hareketlerinin etkilerinin azaltılması için bilgi ve iletişim teknolojilerinden yararlanmışlardır. Kentsel alanlardaki yükün etkisinin azaltılması için de önemli bir rol oynadığı üzerinde durmuşlardır. Benjelloun ve Crainic (2009) şehir lojistiği kavramlarına, modellerine ve planlama konularına genel bir bakış sunmuşlardır. Çok sayıda proje ve teklif analizine dayanarak aynı zamanda eğilimleri, zorlukları ve araştırma yollarını tanımlamışlardır. Taniguchi, 2014 yılında yaptığı çalışmasıyla yaşanabilir şehirler için daha verimli şehir lojistiği ve çevre dostu kentsel nakliye sistemleri üzerinde durmuştur. Kentsel konsolidasyon merkezlerindeki dağıtım sistemleri, belediyelerin bu konudaki rollerine ve diğer alanlara aktarılabildiğine odaklanarak vurgulamıştır. Hausladen vd. (2015) sürekli artan nüfusun şehir lojistiğine çözüm bulma ihtiyacına neden olduğunu savunmuşlardır. Özellikle e-ticaretin istikrarlı bir şekilde büyümesi ve gelişmesinin şehirlerin altyapısına bir yük olduğu üzerinde durmuşlardır. Şehir lojistiği problemlerini çözmeyi hedefleyen kavramlar ileri sürmüşlerdir ve şehir lojistiğindeki kavramların çeşitliliğini göstermeyi hedeflemişlerdir. 
Deniz ve Durdağ, 2015 yılında yaptıkları çalışmada AVM'lerin sunacağı aynı gün teslim hizmetinin şehir lojistiğine etkilerini ve Amerika Birleşik Devletleri uygulama örneklerini incelemişlerdir. Amaçları şehir lojistiğinin paydaşlarının dikkatini çekebilmek ve farkındalık yaratabilmektir. Akçay (2013) yaptığı çalışmasında şehir içi yük taşımasını irdeleyerek elektronik ticaret ile şehir içi yük taşımacılı̆ıının etkileşimini ortaya koymuştur. Somut veriler ile örneklendirmek amacıyla Ankara'da hem mağaza kanalıyla hem de elektronik ortamda müşterilerine hizmet veren bir firma ile yapılan görüşmenin sonuçlarına yer verilmiştir. Tüm bunlar göz önüne alınarak şehir içi yük taşımacılığına çözüm önerileri getirilmiştir. Özalp (2007) çalışmasında ülkemizin çeşitli kentlerinde yapılmış kent içi ulaşım planlama çalışmaları kapsamlı olarak kronolojik bir sıralama içinde incelemiş ve değerlendirmiştir. Bu çalışma şehir ulaşım planlaması çalışmalarında önemli bir envanter çalışma olmuş ve şehir ulaşım planlamasının önemine bir kez daha dikkat çekerek ulaşım sektörü paydaşlarına katkı sağlamıştır.

\section{IZMIR ILINE BAKIŞ}

İzmir; sanayi, ticaret, ulaşım, liman, askerî ve üniversite şehri özelliğiyle ve doğal bir limana, iyi bir ulaşım ağına sahip olması sayesinde Türkiye'nin üçüncü büyük şehridir. Liman büyük bir öneme sahiptir ve ulaşım sistemini de etkiler. Ticaret dâhil çoğu taşımacılık deniz yoluyla sağlanır. İzmir'in lojistik merkez olması için kara üzerinde de lojistik sahaların ve merkezlerin yaratılmasına ihtiyaç duyulmaktadır. Ulaştırma Denizcilik ve Haberleşme Bakanlığınca programa alınan Kemalpaşa Lojistik Merkezi ile ilgili çalışmalar devam etmektedir. Kemalpaşa hem konumunun İzmir'den İç Anadolu'ya açılan koridor üzerinde yer alması, hem de sanayi bölgelerine olan yakınlığı nedeniyle en uygun lojistik merkezdir. İzmir'in güneyinde otoyolun, kara yolu ve demir yolunun kesiştiği noktada bir lojistik merkez kurulması, İzmir'in lojistik potansiyelini ortaya koymasını kolaylaştıracaktır. Bu lojistik merkez, dünyadaki örneklerden yola çıkarak intermodal taşımacılık sistemlerini şehrimize kazandırmalıdır. Aynı zamanda dış ticaret ile uğraşan üyelerin lojistik maliyetlerini azaltmalı, gümrük sahaları ve hizmetleri ile İzmir Alsancak Limanı'nı rahatlatmalı ve İzmir'in çeşitli bölgelerinden gelen yüklerin bir merkezde toplanarak şehre olumsuz etki yaratmadan tüm dünyaya gönderilmesini sağlamalıdır.

İzmir Ticaret Odası'nın araştırmalarına ve analizlerine göre İzmir'in mevcut durumu ve kapasitesi ortaya konmaya çalışılmıştır. Güçlü ve zayıf yönleri tespit edilmiş, oluşabilecek fırsatlar ve tehditler ortaya konmuştur. Bu analizin temel amacı, iç ve dış etkenleri dikkate alarak var olan güçlü yönler ve fırsatlardan en üst düzeyde yararlanacak, tehditlerin ve zayıf yanların etkisini en aza indirecek plan ve stratejiler geliştirmektir. Tablo 1'de İzmir'in SWOT analizi gösterilmektedir.

Tablo 1: İzmir'in SWOT Analizi

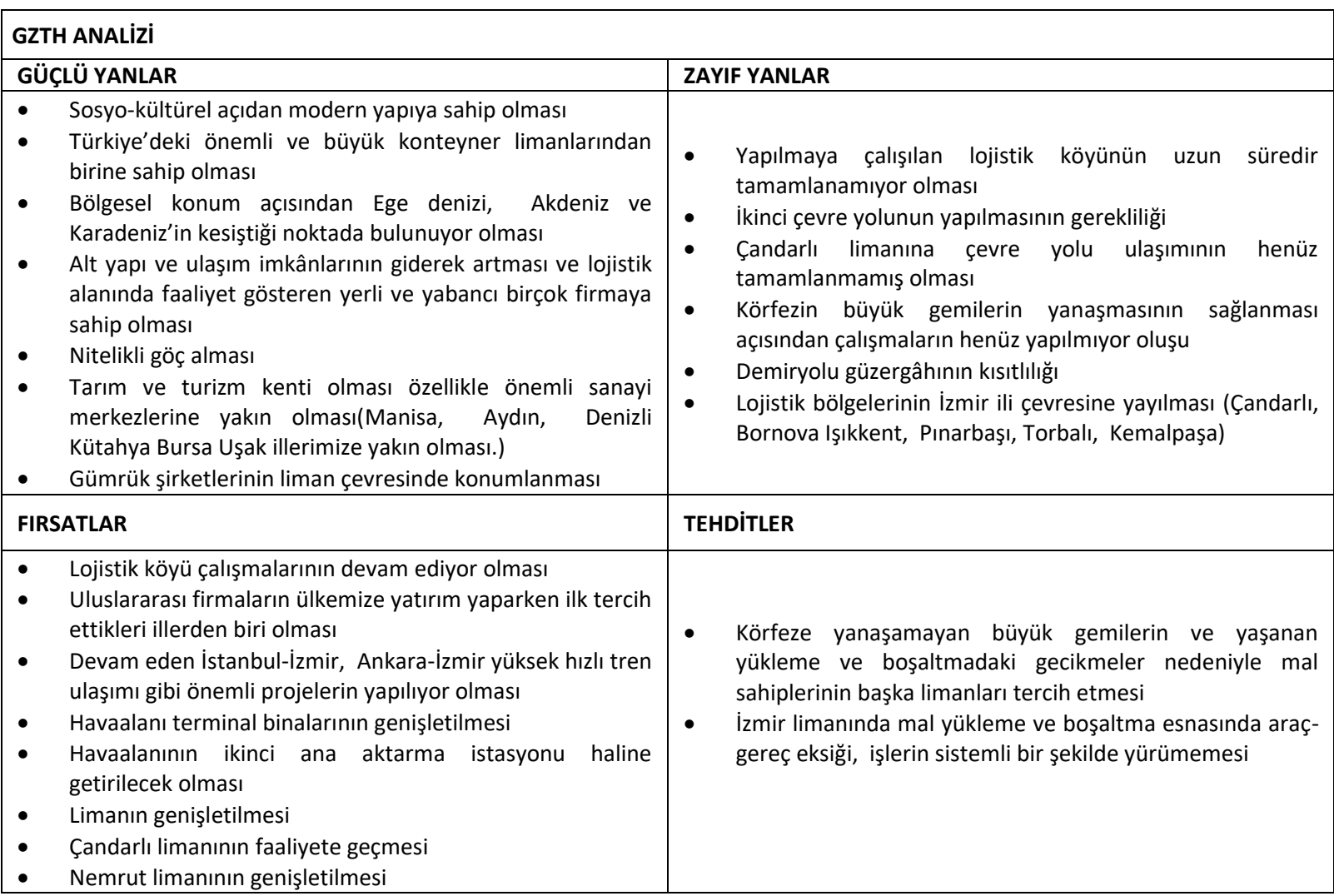


SWOT Analizine göre, İzmir sahip olduğu sosyokültürel özellikler, konum itibariyle kesişim noktasında bulunması, nitelikli göç alması, tarım ve turizm kenti olması açısından güçlü durumda bulunmaktadır. Ancak ulaşımda yaşanan bazı problemler (çevre yolu yetersizliği, demiryolu güzergâhının kısıtılı̆̆ı gibi zayıf yönleri de bulunmaktadır. Zayıf yönleri bulunsa da lojistik köyü çalışmalarının devam ediyor olması, ulaşım açısından önemli faaliyetlere sahip olması, havaalanı için yeni projelere sahip olması ve yeni limanların faaliyete geçmesi İzmir ilinin gelişimi için önemli fırsatlardır. Bu fırsatlara az da olsa engel olabilecek tehdit unsuları körfeze yanaşamayan büyük gemilerin ve yaşanan yükleme ve boşaltmadaki gecikmeler nedeniyle mal sahiplerinin başka limanları tercih etmesi ve İzmir limanında mal yükleme ve boşaltma esnasında araç-gereç eksiği, işlerin sistemli bir şekilde yürümemesidir.

\section{ARAŞTIRMANIN AMACI VE METHODOLOJi}

Bu çalışma iki ana kısımdan oluşmaktadır. Birinci aşamada şehir lojistiği ile ilgili literatür taraması yapılmıştır. Bugüne dek oluşturulan raporlardan şehir lojistiği ile ilgili istatistiki bilgiler elde edinilmiş ve çalışmaya alt zemin hazırlanmıştır.

İkinci aşamada ise İzmir ilinde yaşayan 150 kişiyle yüz yüze, yol üzerinde, belirli bölgeleri kapsayacak şekilde detaylı bir anket çalışması yapılmıştır. Yapılan çalışma, "İzmir Büyükşehir Belediyesi Konak ilçesi için "izmir Tarih Sürdürülebilir Ulaşım Projesi" kapsamında yapılmış olan anketten uyarlanmıştır.

12-19 Ocak 2018 tarihleri arasında yapılan anket, 65 sorudan ve toplamda 4 bölümden oluşmaktadır. 1. bölümde görüşme yapılan kişilerin demografik özellikleri yer almaktadır. Bu bölüm yaş, cinsiyet, eğitim seviyeleri gibi soruları içermektedir. Bu bölümdeki sorular ile yaş, cinsiyet, eğitim seviyesi gibi özelliklerin şehir lojistiği ile bağlantısı analiz edilmek istenmiştir. Bu sayede cinsiyete, yaşa ve eğitim seviyesine göre şehir algısındaki farklııkların test edilmesi amaçlanmıştır.

Anketin 2. bölümü çevre ve ulaşım hakkında bilgi almaya yönelik soruları içermektedir. Katılımcıların çevre ve ulaşım hakkındaki görüşleri alınarak var olan sorunlara sürdürülebilir çözüm yolları üretmek amaçlanmıştır. Bu bölümde katılımcılar çevre kirliliği gibi çevre ile ilgili ve ulaşım ile ilgili sorunları belirtmişlerdir.

Anketin 3. bölümünde ankete cevaplayan kişilerin şehirde en çok şikâyet ettikleri unsurların tespiti için sorular bulunmaktadır. Bu sorular dokunsal yüzeylerin durumu, bisiklet yollarının durumu, toplu taşıma olanakları, çocuk ve oyun alanlarının yeterliliği gibi şehir içerisinde önemli olan etkenleri sorgulamaktadır. Bu sayede katılımcıların sosyal yaşamını etkileyen sorunların kolaylıkla belirlenmesi ve bu sorunlara çözüm yolları bulunması amaçlanmıştır.

Anketin son bölümü ise bisiklet kullanıcılarına ayrılmıştır. Bisiklet kullanıcısı olmayan kişilerden bu bölümü cevaplamamaları istenmiştir. Bu bölümde bisiklet yolları, bisiklet park alanlarının yeterliliği, uygun zemin kaplamalarının varlığı, bisiklet yollarının toplu taşıma ile entegrasyonu, elektrikli şarj istasyonlarının yeterliliği sorgulanmıştır. Bu sayede bisiklet kullanıcılarının sorunlarına çözüm yolları bularak, bisiklet kullanımını arttırmak amaçlanmıştır.

Çalışmada cinsiyet, yaş, eğitim seviyesinin sürdürülebilirlik algısı arasındaki ilişkisini ölçmek için t-testi ve tek yönlü varyans analizleri yapılmıştır. Ayrıca, şehir de karşılaşılan başlıca şikâyetler sıralanarak günlük hayat içerisinde yaşanan asıl problemler belirlenmiştir. Son analizde ise bisiklet kullanımı ile ilgili şikâyetler belirlenmiştir.

Bu çalışma ile İzmir ili şehir lojistiği için detaylı bilgi toplanmaya çalışılmıştır. Anket cevapları kişilerin yaşam standartlarına ve beklentilerine göre farklı cevaplar ortaya koymuştur.

\section{ARAŞTIRMA BULGULARI}

\subsection{Demografik Bilgiler}

Demografik bilgiler, tanımlayııı istatistik kullanılarak elde edilmiştir. Buna göre katılımcıların \%46'sı kadın, \%54'ü erkektir. Bu kişilerin hiç biri fiziksel ya da görme engelli değildir. Bu yüzde dağıımının gerçek kitleyi de temsil ettiği ve yansıttığı söylenebilir. Ankete katılanların \%3'ü 18 yaş altı, \%30'u 18-25 yaş arası, \%45'i 25-40 yaş arası, \%15'i 40-60 yaş arası, \%7'si ise 60 yaş üstü kişilerdir. Katılımcıların \%2'si ilkokul mezunu olmayan, \%5'i ilköğretim mezunu, \%5'i ortaokul mezunu, \%28'i lise mezunu, \%58'i üniversite mezunu ve \%2'si lisansüstü eğitim almışlardır. Katılımcıların \%21'sinin öğrenci, \%51'inin çalışan, \%16'sinin çalışmayan ve \%12'sinin emekli olduğu belirlenmiştir. Bu veriden yola çıkılarak, katılımcıların yaklaşık olarak \%72'sinin sürekli ve düzenli olarak sokakları ve ulaşım araçlarından yararlandığı, \%28'inin ise daha düzensiz bir şekilde sokakları ve ulaşım araçlarından yararlandığı belirtilebilir. Bu sayede sürekli ve düzenli olarak sokakları kullanan ve ulaşım araçlarından yararlanan katılımcıların daha belirleyici cevaplar vermiş olduğu söylenebilir. Katılımcıların tamamı İzmir ili sakinlerinden oluşmaktadır. Anketlere cevap verenlerin $\% 45$ 'i aynı zamanda katılımın en büyük kısmını oluşturan kişiler Bornova bölgesinde ikamet ettiğini belirtmiştir. Bunun dışında katılımcıların \%29’u Menemen ilçesinde, \%11'i Konak ilçesinde, \%8'i Karşıyaka ilçesinde ve \%7'si Karabağlar ilçesinde ikamet ettiğini belirtmiştir. 


\subsection{Sürdürülebilir Şehir Algısının Cinsiyet, Yaş ve Eğitim Süresine Göre Farklılık Göstermesinin Test Edilmesi}

Bu bölümde, sürdürülebilir şehir algısının; anketi cevaplayanların cinsiyetine, yaşına ve eğitim sürelerine göre anlamlı bir farklılık olup olmadığı incelenmiştir. Cinsiyet unsuru ile ilgili t-test analizi yapılmış ve sonuçlar Tablo 2'de gösterilmiştir.

Tablo 2: Cinsiyete Göre Sürdürülebilir Şehir Algısı Farklılığının Testi

\begin{tabular}{|c|l|l|l|l|l|l|}
\hline Cinsiyet & N & Ortalama & Std. Sapma & $\mathrm{t}$ & $\mathrm{P}$ & $\begin{array}{l}\text { Ortalama } \\
\text { farkı }\end{array}$ \\
\hline Erkek & 70 & 2,371 & 1,684 & 1,501 & 0,048 & -788 \\
Kadın & 80 & 4,864 & 0,527 & & & \\
\hline
\end{tabular}

Tablo 2'de belirtildiği üzere, anketi cevaplayanların cinsiyetleri arasındaki ortalama değerleri birbirinden farklıdır ve $p$ değeri 0, 048 çıkmıştır. Bu durumda sürdürülebilir şehir algısı cinsiyete göre anlamlı bir fark göstermektedir denilebilir.

Yaş gruplarına ve eğitim seviyelerine göre sürdürülebilir şehir algısının ortalamalarının ve bu ortalamaların karşılaştırılması için tek yönlü varyans analizi (One-Way ANOVA) yapılmış ve sonuçlar Tablo 3 ve Tablo 4'de verilmiştir.

Tablo 3: Yaş Gruplarına Göre Tek Yönlü Varyans Analizi Sonuçları

\begin{tabular}{|c|c|c|c|c|c|}
\hline Yaş Aralıkları & $\mathrm{N}$ & Ortalama & Std.Sapma & $\mathrm{F}$ & $P$ \\
\hline $12-20$ & 5 & 3,12 & 0,40 & \multirow{5}{*}{3,337} & \multirow{5}{*}{0,022} \\
\hline $21-25$ & 45 & 3,06 & 0,63 & & \\
\hline $26-40$ & 67 & 3,27 & 0,66 & & \\
\hline $41-60$ & 23 & 3,86 & 0,54 & & \\
\hline $61-100$ & 10 & 3,48 & 0,48 & & \\
\hline
\end{tabular}

Varyans analizi sonuçlarına göre; $p$ değeri 0,222 olarak hesaplanmıştır. $(p<0,05)$ Yani, sürdürülebilir şehir algısı yaş gruplarına göre anlamlı farklıık göstermektedir.

Tablo 4: Eğitim Seviyelerine Göre tek Yönlü Varyans Analizi Sonuçları

\begin{tabular}{|c|c|c|c|c|c|}
\hline Eğitim Seviyeleri & $\mathrm{N}$ & Ortalama & Std.Sapma & $\mathrm{F}$ & $p$ \\
\hline Yok & 2 & 3,37 & 0,66 & \multirow{5}{*}{1,756} & \multirow{5}{*}{0,015} \\
\hline İlköğretim & 16 & 4,06 & 0,50 & & \\
\hline Lise & 42 & 4,06 & 0,50 & & \\
\hline Üniversite & 87 & 3,97 & 0,61 & & \\
\hline Lisansüstü & 3 & 3,67 & 0,87 & & \\
\hline
\end{tabular}

Analiz sonucunda $p$ değeri 0,015 olarak hesaplanmıştır. P değeri 0,05 değerinden küçük çıktığından sürdürülebilir şehir algısı eğitim seviyelerine göre anlamlı farklılık gösterdiği belirtilebilir.

Uygulanan anketin 3. ve 4. bölümünde ise İmir'in sürdürülebilir şehir olmasında ki en büyük engeller ve başlıca şikâyetler ile bisiklet yolları hakkında görüşler sorulmuştur. Özet sonuçlar Tablo 5 ve Tablo 6'da yer almaktadır.

Tablo 5: Başlıca Şikâyetler

\begin{tabular}{|l|l|l|l|l|l|}
\hline No & Şikâyetler & Yetersiz & $\%$ & Yeterli & $\%$ \\
\hline 1 & Dokunsal Y. & 143 & $\% 95$ & 7 & $\% 5$ \\
\hline 2 & Bisiklet Y. & 125 & $\% 83$ & 25 & $\% 17$ \\
\hline 3 & Otopark Olanak. & 111 & $\% 74$ & 39 & $\% 26$ \\
\hline 4 & Yaya A. & 81 & $\% 54$ & 69 & $\% 46$ \\
\hline 5 & Toplu Taşıma & 79 & $\% 53$ & 71 & $\% 47$ \\
\hline 6 & Dinlenme A. & 78 & $\% 52$ & 72 & $\% 48$ \\
\hline 7 & Çocuk \&Oyun A. & 77 & $\% 35$ & 73 & $\% 65$ \\
\hline
\end{tabular}

Anket çalışmasının 3.bölümünde başlıca şikâyetler sıralanmıştır. Tablo 5 'te belirtildiği üzere ortaya çıkan başlıca sonuçların en önemlileri dokunsal yüzeylerin azlı̆̆ı, bisiklet yollarının azlı̆̆ı ve otopark olanaklarının yetersiz olması, yaya alanlarının 
azlığı, toplu taşımanın yetersizliği, dinlenme alanlarının ve çocuk oyu alanlarının azlığıdır. Ankete katılan kişilerin \%95’i dokunsal yüzeyleri yetersiz bulmaktadır.

Tablo 6: Bisiklet Yolu ile ilgili Bilgiler

\begin{tabular}{|l|l|l|l|}
\hline No & Şikâyetler & $\begin{array}{l}\text { Yetersiz } \\
\%\end{array}$ & $\begin{array}{l}\text { Yeterli } \\
\%\end{array}$ \\
\hline 1 & Bisiklet Park Alanları & $\% 67$ & $\% 33$ \\
\hline 2 & Bisiklet Yolları & $\% 100$ & - \\
\hline 3 & Uygun Zemin Kaplama & $\% 26$ & $\% 74$ \\
\hline 4 & Toplu Taşıma ile Entegrasyon & $\% 68$ & $\% 32$ \\
\hline 5 & Elektrikli Şarj İstasyonları & $\% 95$ & $\% 5$ \\
\hline 6 & Bisiklet Kiralama Alanları & $\% 15$ & $\% 85$ \\
\hline
\end{tabular}

Yapılan anketin son aşaması bisiklet alanlarını analiz etmeye yöneliktir. Tablo 6'da gösterildiği üzere ankete katılan kişilerin \%100'ü bisiklet yollarını yetersiz bulur iken \%95'i elektrikli şarj istasyonlarının yetersizliğinden şikâyet etmektedir. Bisiklet alanları için diğer önemli şikâyetler ise bisiklet park alanlarının yetersizliği, zemin kaplamalarının uygunsuzluğu, bisiklet alanlarının toplu taşıma ile entegrasyonunun olmaması ve bisiklet kiralama alanlarının yetersizliğidir.

\section{SONUÇ VE ÖNERILER}

Bu çalışmada, İzmir ilinin sürdürülebilir şehir olma özelliğini irdelemek için anket çalışması yapılmıştır. İzmir ilinde en az 10 yıldır ikamet eden 150 kişi, 65 soru ve toplamda 4 bölümden oluşan anketi cevaplamışlardır. İlk olarak sürdürülebilir şehir algısının yaş, cinsiyet ve eğitim seviyesi ile anlamlı bir farklılık gösterdiği tespit edilmiştir. Anketin 3.bölümünde araştırma bulguları kısmında da görüldüğü gibi başlıca şikayetler tespit edilmiştir. Bu tespit sonucunda dokunsal yolların sürekliliğinin sağlanması ve sıklaştırılması, bisiklet yollarının sürekliliğinin sağlanması ayrıca otopark olanaklarının geliştirilmesi gerekliliği görülmektedir. Anketin son bölümünde yer alan İzmir' de bisiklet kullanım alanları için sürekli bisiklet kullanıcılarına bir değerlendirme yapılmış ve başlıca şikâyetler sıralanmıştır. Tablo $6^{\prime}$ da da görüleceği üzere bisiklet kullanım alanlarında bisiklet yollarının sürekliliğinin sağlanması, elektrikli şarj istasyonlarının sıklaştırılması, toplu taşıma ve entegrasyon konusunda iyileştirmeye gidilmesi, bisiklet park alanlarının sıklaştırılması gerektiği saptanmıştır.

Gelecek çalışmalar için, özellikle İzmir'in ilçe bazında daha geniş kitlere aynı anketin yapılması ve ilçe bazında şikâyetlerin sıralanıp yetkili kişilere ulaştırılması amaçlanmaktadır. Öneri olarak İzmir ili içerisindeki metro istasyonlarına Peron Ayırıcı Kapı Sistemi gelmesidir. Bu sistem başka güvenlik amaçlı olup metro tren hattı ile istasyondaki yolcu peronunu birbirinden ayırır. Buna ek olarak hissedilebilir zeminler söz konusu kapı sistemine göre düzenlendiğinde görme engelli vatandaşlarımızın tren kapılarııın tam olarak nerede duracağına dair bir fikir sahibi olmalarına da yardımcı olur.

\section{KAYNAKLAR}

Anand, N., Quak, H., van Duin, R., Tavasszy, L. (2012). City logistics modelling efforts: trends and gaps a review. The Seventh International Conference on City Logistics, Procedia-Social and Behavioral Sciences, 39, 101-115.

Akbulut, F. (2016). Kentsel ulaşım hizmetlerinin planlanması ve yönetiminde sürdürülebilir politika önerileri. Kastamonu Üniversitesi İktisadi ve İdari Bilimler Fakültesi Dergisi, 11 (1), 336-355.

Akçay, M. E. (2013). Kent içi yük taşımacılığı ve e-ticaretin etkileşimi üzerine bir araştırma. Gazi Üniversitesi, Fen Bilimleri Enstitüsü. Yüksek Lisans Tezi.

Benjelloun, A., Crainic, T. G. (2009). Trends, challenges, and perspectices in city logistics. Simulating the Impact of New Australian "BiModal" Urban Freight Terminals, 45-51.

Büyüközkan, G., Soncul, M., Tanyaş, M. (2012). Kentsel lojistik yapısının modellenmesi ve analizi. 1.Ulusal Lojistik ve Tedarik Zinciri Kongresi Bildiri Kitabı, Necmettin Erbakan Üniversitesi, Konya, 10-12.05.2012, 587-595.

Cirit, F. (2014). Sürdürülebilir kent iç̧i ulaşım politikaları ve toplu taşıma sistemlerinin karşılaştırılması. T.C. Kalkınma Bakanlığı, Uzmanlık Tezi, Yayın No: 2891.

Comendador, J., Lopez-Lambas, M., Monzon, A., (2012). A GPS analysis for urban freight distribution. The Seventh International Conference on City Logistics, Procedia-Social and Behavioral Sciences, 39, 521-533.

Crainic, T., Ricciardi N. (2004). Advanced freight transportation systems for congested urban areas. Transportation Research Part C: Emerging Technologies, 12(2), 119-137.

Çalışkan, A., Kalkan, M., Ozturkoglu, Y. (2017). City logistics: problems and recovery proposals. International Journal of Logistics Systems and Management, 26(2), 145-162. 
Dalgakıran, A. B., Öztürkoğlu, Y. (2017). Scale and relationship analysis for Turkish furniture sector. Business \& Management Studies: An International Journal, 5(1), 147-161.

Deniz, Ş. Ü., Durdağ, C. (2015). Alışveriş merkezlerinin aynı gün teslim hizmeti sunmasının kentsel lojistiğe etkileri ve ABD uygulama örnekleri. IV. Ulusal Lojistik ve Tedarik Zinciri Kongresi, Gümüşhane, 21-23 Mayıs 2015.

Dodson, J., Mees, P., Stone, J., Burke, M. (2011). The principles of public transport network planning: a review of the emerging literature with select examples. Griffith University Urban Research Program, 15.

Erdumlu, R. M. (2006). Kentsel lojistik ve lojistik köy uygulaması. İstanbul Teknik Üniversitesi Fen Bilimleri Enstitüsü, Yüksek Lisans Tezi, İstanbul.

Erel, A., Yardım, M. S., Gursoy, M. (1995). Ülkemiz ulaştırma planlama ve yönetimi konusundaki veri gereksinimi vebir öneri. 3. Ulaştırma Kongresi, Kongre Sempozyum Bildiri Kitabı, 107-125.

Gülhan, G., Ceylan, H., Özuysal, M., Ceylan, H. (2013). Impact of utility-based accessibility measures on urban public transportation planning: A Case Study of Denizli, Turkey. Cities, 32, 102-112.

Haldenbilen, S., Murat, Y., Baykan, N., Meriç, N. (1999). Parking problems in cities: sample of Denizli. Pamukkale Üniversitesi Mühendislik Bilimleri Dergisi, 5 (2), 1099-1108.

Hausladen, I., Dachsel, B., Haas, A. (2015). Trends and potentials of city logistics concepts in the age of e-commerce from a sustainability perspective. HHL Leipzig Graduate School of Management, 147, ISSN 1864-4562 (Online version).

İnaç, H., Tanyaş, M. (2012). İstanbul'un kentsel lojistik analizi ve çözüm önerilerinin AHP ile değerlendirilmesi. 1.Ulusal Lojistik ve Tedarik Zinciri Kongresi Bildiri Kitabı, Necmettin Erbakan Üniversitesi, Konya, 10-12.05.2012, 137-147.

Karadeniz, V., Akpınar E. (2011). Türkiye’de lojistik köy uygulamaları ve yeni bir lojistik köy önerisi. Marmara Coğrafya Dergisi, 24(1), 49-71.

Kurt, C. (2010). Türkiye'de ulaştırma sektörü içerisinde lojistiğin yeri ve önemi. İstanbul Üniversitesi Sosyal Bilimler Enstitüsü İktisat Anabilim Dalı İktisat Politikası Bilim Dalı Yüksek Lisans Tezi, İstanbul.

Lindholm, M. (2010). A sustainable perspective on urban freight transport: factors affecting local authorities in the planning procedures. The sixth international conference on city logistics, Procedia Social and Behavioral Sciences, 2, 6205-6216.

Morana, J., Gonzales-Feliu, J. (2010). Sustainable supply chain management in city logistics solutions: an experience's comeback from Cityporto Padua (Italy). Proceedings of the 3rd International Conference on information systems, Logistics and Supply Chain Creating value through green supply chains, ILS 2010- Casablanca (Morocco), April 14-16

Özalp, M., Öcalir, E. V. (2008). Türkiye'deki kent içi ulaşım planlaması çalışmalarının değerlendirilmesi. METU Journal of the Faculty of Architecture, 25 (2), 71-97.

Saatçioğlu, C., Yaşarlar, Y. (2012). Kent içi ulaşımda toplu taşımacılık sistemleri: i̇stanbul örneği. Kafkas Üniversitesi İktisadi ve İdari Bilimler Fakültesi Dergisi, 3(3), 117-144.

Sabegh, M. H. Z., Ozturkoglu, Y., Kim, T. (2016). Green supply chain management practices' effect on the performance of Turkish business relationships. International Journal of Supply and Operations Management, 2(4), 982.

Spence, M., Annez, P. C., Buckley, R. M. (2009). Urbanization and growth: commission on growth and development. Retrieved from: https://openknowledge.worldbank.org/handle/10986/2582.

Tadić, S., Zečević, S., Krstić, M. (2015). City logistics-status and trends. International Journal for Traffic \& Transport Engineering, 5(3), 319343.

Taniguchi, E. (2014). Concepts of city logistics for sustainable and liveable cities. Procedia - Social and Behavioral Sciences, 151, 310-317.

Taniguchi, E., Tamagawa, D. (2005). Evaluating city logistics measures considering the behavior of several stakeholders. Journal of the Eastern Asia Society for Transportation Studies, 6, 3062-3076.

Taniguchi, E., Thompson, R., Yamada, T. (2015). New opportunities and challenges for city logistics. Transportation Research Procedia, 12, $5-13$

Tanyaş, M. (2013). Kentsel lojistik ve lojistik merkezler. Lojistik Yatırımları Konferansı, Maltepe Üniversitesi, İstanbul.

Van Rooijen, T., Quak, H. (2014). City logistics in the European CIVITAS Initiative. Procedia-Social and Behavioral Sciences, 125, 312-325.

Yaliniz, P., Bilgic, S., Vitosoglu, Y., Turan, C. (2011). Evaluation of urban public transportation efficiency in Kutahya, Turkey. Procedia-Social And Behavioral Sciences, 20, 885-895.

Yazar, K. H. (2006). Sürdürülebilir kentsel gelişme çerçevesinde orta ölçekli kentlere dönük kent planlama yöntem önerisi. Ankara Üniversitesi Sosyal Bilimler Enstitüsü Kamu Yönetimi ve Siyaset Bilimi (Kent ve Çevre Bilimleri) Anabilim Dalı, Doktora Tezi, Ankara.

Zhang, Q., Wu, Y. (2009). Research on the city logistics development evaluation system based on fuzzy mathematics. IEEE, January 2009, 4244-4639. 